University of Nebraska - Lincoln

DigitalCommons@University of Nebraska - Lincoln

November 2006

\title{
The Role of Visual Ornamentation in Female Choice of a Multimodal Male Courtship Display
}

\author{
Eileen Hebets \\ University of Nebraska - Lincoln, ehebets2@unl.edu \\ K. Cuasay \\ Cornell University, Ithaca, NY \\ P. K. Rivlin \\ Cornell University, Ithaca, $N Y$
}

Follow this and additional works at: https://digitalcommons.unl.edu/bioscihebets

Part of the Behavior and Ethology Commons

Hebets, Eileen; Cuasay, K.; and Rivlin, P. K., "The Role of Visual Ornamentation in Female Choice of a Multimodal Male Courtship Display" (2006). Eileen Hebets Publications. 18.

https://digitalcommons.unl.edu/bioscihebets/18

This Article is brought to you for free and open access by the Papers in the Biological Sciences at DigitalCommons@University of Nebraska - Lincoln. It has been accepted for inclusion in Eileen Hebets Publications by an authorized administrator of DigitalCommons@University of Nebraska - Lincoln. 


\title{
The Role of Visual Ornamentation in Female Choice of a Multimodal Male Courtship Display
}

\author{
Eileen A. Hebets, School of Biological Sciences, University of Nebraska-Lincoln, Lincoln, NE \\ K. Cuasay, Department of Neurobiology and Behavior, Cornell University, Ithaca, NY \\ P. K. Rivlin, Department of Neurobiology and Behavior, Cornell University, Ithaca, NY
}

Corresponding author: E. A. Hebets, School of Biological Sciences, 348 Manter Hall, University of Nebraska-Lincoln, Lincoln, NE 68588, USA. Email: ehebets2@unl.edu

\begin{abstract}
The courtship behavior of male Schizocosa uetzi wolf spiders incorporates both visual and seismic signals into a multimodal display. These two signals have been shown to interact in such a manner that the seismic signal alters a female's response to the visual signal, leading to a putative increased importance of visual signaling in the presence of a seismic signal. Experiments leading to this attention-focusing hypothesis relied in part on the video playback technique, eliciting the question of its significance under more biologically relevant conditions. Here, we directly examine female mate choice of males with differing visual signals (foreleg pigmentation) both in the presence and absence of a seismic courtship signal. We first quantified the natural variation of male foreleg pigmentation within a population of $S$. uetzi. The proportion of the tibia covered in pigmentation was found to be positively correlated with male weight, suggesting that this signal may convey reliable information about male size. Visual signals of live males were then manipulated into two treatments: black and brown male foreleg tibias, representing the extreme ends of the natural variation found. The seismic signaling environment was also manipulated into two treatments: seismic signal present and absent. Mating frequency was higher in the presence of a seismic signal than in its absence, but there was no interaction between the seismic and visual signaling treatments. Females mated with black and brown males equally whether a seismic signal was present or absent. This study suggests that inexperienced females do not distinguish between males of different manipulated foreleg pigmentations in mate-choice decisions, even when in the presence of a seismic courtship signal.
\end{abstract}

\section{Introduction}

Recent empirical studies highlight the importance and prevalence of inter-signal interactions in complex signaling displays across multiple animal taxa (reviews see Candolin 2003; Hebets \& Papaj 2005). However, while signal interactions may be common, they are often difficult to study. The examination of inter-signal interactions typically requires the controlled manipulation of one or more signal or component of a complex display. In the animal taxa where such studies are feasible, they are, by necessity, often conducted in the laboratory under highly artificial conditions, rendering the significance of their results for natural situations uncertain. While these studies are unquestionably important and can address the existence of inter-signal interactions, they cannot always address the natural relevance of these interactions. There are no doubt incredible advantages to using artifi- 
cial experimental designs; however, such approaches are often limiting in their scope. Here, we build on results of prior video-playback studies by using manipulations of live individuals to explore a previously described interaction between multimodal male courtship signals in the wolf spider Schizocosa uetzi.

Male Schizocosa spiders often use both visual and seismic signals when courting a female (Uetz \& Denterlein 1979; Stratton \& Uetz 1981, 1986; Stratton 1983; Stratton \& Lowrie 1984; Hebets et al. 1996). All species within the genus have a seismic courtship component and variations exist among species in the degree to which visual signaling plays a role in courtship displays as well as the degree to which male forelegs are ornamented. Males of some species possess either black pigmentation alone or black brushes in addition to black pigmentation on some segments of their forelegs, while males of other species possess brown forelegs devoid of any pigmentation. Furthermore, the courtship display of some species involves rapid tapping or waving of the forelegs, while other species lack any foreleg movement during courtship. Several elegant studies have examined female responses to isolated visual and/or seismic components of courtship displays across multiple Schizocosa species (McClintock \& Uetz 1996; Scheffer et al. 1996; Hebets \& Uetz 1999), but only recently have studies attempted to experimentally assess female receptivity to different combinations of these signals.

An earlier study used digitized courtship sequences that were manipulated to represent varying levels of male foreleg ornamentation to test female receptivity responses to male courtship ornamentation across several Schizocosa species (Hebets \& Uetz 2000). For each of four different species, male courtship displays were digitized to create a short courtship loop. For each species, the original digitized loops were manipulated to generate three different visual stimuli: (1) a "no ornament" video sequence in which no ornamentation was present on the male forelegs, (2) a "pigment only" video sequence in which black pigmentation was present on the male's forelegs, and (3) a "brushes" video in which the forelegs possessed black brushes in addition to black pigmentation. For each species, conspecific females were shown all three video sequences on small television screens and their receptivity responses were scored.

Schizocosa uetzi was one of the species used in the above-described study. Within a single population, males of $S$. uetzi vary in their degree of foreleg pigmentation, with the foreleg tibias of some males appearing much darker than the foreleg tibias of other males.
As such, for $S$. uetzi, the "no ornament" video represented the removal of pigmentation on the male's foreleg tibia, the "pigment only" video was a control, and the "brushes" video represented an exaggerated form of ornamentation involving a potentially novel trait: brushes in addition to black pigmentation. These manipulated video sequences were played back to $S$. uetzi females in two separate studies: first in the absence of a seismic courtship signal (Hebets \& Uetz 2000) and then in the presence of a seismic courtship signal (Hebets 2005). Interestingly, females only distinguished among visual stimuli with an increase in receptivity to videos with increased male ornamentation while in the presence of a seismic signal. These results, in addition to results from a third experiment (Hebets 2005), suggest that the seismic courtship signal of $S$. uetzi males alters a female's response to the visual signal (Hebets 2005).

While the results of the above-mentioned studies clearly demonstrate an interaction between the visual and seismic courtship signals in $S$. uetzi, the relevance of this interaction under natural conditions is unclear for the following two reasons. First, the difference in female receptivity to varying visual stimuli in the presence of a seismic signal was only seen with video stimuli involving the artificially exaggerated/novel trait ("brushes" video vs. "no ornamentation" video), not with the naturally occurring foreleg variation ("pigment only" video). Secondly, female receptivity displays were used as a proxy for female mate choice in these experiments. While a successful copulation is typically preceded by a female receptivity display, receptivity displays are not always followed by a successful copulation (E. A. Hebets, pers. obs.). Hence, the present study uses a more biologically relevant experimental design that assesses actual copulation frequency as opposed to female receptivity in an attempt to explore the natural relevance of the previously described attention-altering interaction between the visual and seismic courtship signals of $S$. uetzi.

We first quantified the natural variation found in $S$. uetzi male foreleg ornamentation. Then, using live males and females that were allowed to interact through to copulation, we independently manipulated both the live male visual signal and the seismic signaling environment in a $2 \times 2$ design. In order to test the hypothesis that females pay more attention to the visual signal in the presence vs. absence of a seismic signal, we examined mating frequencies across the four experimental treatments (black foreleg/seismic signal present $(\mathrm{bk}+/ \mathrm{s}+)$; black 
forelegs/seismic signal absent ( $\left.\mathrm{bk}+/ \mathrm{s}^{-}\right)$; brown forelegs/ seismic signal present $(\mathrm{br}+/ \mathrm{s}+)$; and brown forelegs/seismic signal absent $\left(\mathrm{br}+/ \mathrm{s}^{-}\right)$. We found mating frequency to be higher in the presence vs. absence of a seismic signal, however no interactions were found between seismic and visual signal treatments.

\section{Methods}

\section{Spiders}

Schizocosa uetzi is a medium-sized wolf spider found throughout the southeastern United States. Mature males of this species have varying degrees of black pigmentation on the middle portion of the tibiae of their forelegs but do not possess black brushes of hairs. The variation in ornamentation consists of differences in both the area of the tibia pigmented as well as the darkness of the pigmentation. During courtship, males typically stand in one place and produce a seismic signal using a stridulatory organ located on their pedipalps. Intermittently, concurrent with the production of their seismic courtship song, they slowly lift one foreleg. As the foreleg is lifted, the femur/patella joint as well as the tibia/metatarsus joint is held between $45^{\circ}$ and $90^{\circ}$ angles in what is referred to as a foreleg arch.

Immature males and females were collected at night from sites in Lafayette and Marshall Counties in northern Mississippi in May 2002 for the mate-choice trials and May 2003 for the visual signal quantification. All the specimens were brought back to the laboratory where they were housed individually in plastic boxes. They were provided with a constant source of moisture, fed three to five crickets once a week and were kept at approx. $25^{\circ} \mathrm{C}$, under a $12: 12 \mathrm{~h}$ (light : dark) photo period regime. Behavioral experiments were run in early June 2002.

\section{Quantifying the Visual Signal}

Fifty-four unmanipulated males (i.e. no nail polish treatment) used in a previous experiment (Hebets 2005) were killed and stored in 70\% alcohol. The right foreleg of every male was removed, dehydrated, cleared in methyl salicylate and mounted on a microscope slide with the exterior lateral side facing up, using Entellan mounting media (EMS, Inc., Hatfield, PA, USA). Under a Leica MZFLIII stereoscope (Leica Technologies, San Jose, USA), a digital image was taken of the male foreleg using a Leica DFC500 digital camera. All images were captured using the same illumination settings and magnification. Subsequently, using Image-Pro Discovery software (Media Cybernetics Inc., Silver Spring, MI, USA) (version 4.5) and Photoshop (version 7.0), we analyzed the visual ornamentation of the tibia. Using Photoshop, we determined the brightness (grayscale value) of pixels along the entire surface of the segment of each male's foreleg to determine minimum and maximum brightness values. Using the darkest pigment found, we used Image-Pro software to determine the area of the tibia and patella covered with that pigment $( \pm$ a tolerance interval or range that was empirically determined to be 680 for RGB36 images). The entire area of the tibia was measured and used to calculate the percentage of the segment covered with ornamentation. The difference between the lightest and darkest grayscale pigment gives a value of degree of contrast within the given segment. Using the measurement tools of Image-Pro, we also measured the lengths of all foreleg segments in order to get a measure of relative male size.

\section{Male Foreleg Manipulations}

Upon maturation, males were randomly assigned to one of two foreleg treatment groups: black vs. brown. Because individuals were randomly assigned treatments, some of the males assigned to the "brown" treatment may have had foreleg tibias that were black, however the brown nail polish covered up any pre-existing black pigmentation. Individual males were placed in a quart-size Ziplock bag with the tip of one bottom corner cut off. Males were guided to the bottom cut corner where soft forceps were used to gently pull the foreleg(s) through the bag, leaving the rest of the body and legs restrained within the bag. Using a small paint brush, the dorsal and ventral surface of the tibia and patella of both forelegs were painted with nail polish under a dissecting scope. For the black treatment nail polish, we used NailSlicks midnight metal, 551 and we used NailSlicks bronze ice, 150 CoverGirl (Proctor \& Gamble Company, Cincinnati, $\mathrm{OH}, \mathrm{USA}$ ) as the brown nail polish. This male foreleg manipulation technique is identical to that described in Hebets (2003), and there are no known harmful side effects.

\section{Mate-Choice Trials}

The mate-choice experiment was a fully crossed $2 \times 2$ design with a manipulation of the seismic environment approximating the two treatments of: seismic signal present vs. absent, and a visual signal manipulation of: 
black vs. brown male forelegs. Granite was used as the courting substratum for the treatment in which the seismic signal was removed while filter paper provided the courting substratum for the seismic signal present trials. Granite has been used in other studies to remove seismic signals because it does not transmit seismic signals effectively (Elias et al. 2004; Hebets 2005) and thus allows for the removal of the seismic signal without physical manipulations of either the signaler or the receiver. In a study examining seismic signal attenuation on natural substrates, when compared with a leaf, granite reduced the seismic signal by more than $60 \mathrm{~dB}$ at all measurement distances (increments of $5 \mathrm{~mm}$ from 0 to $20 \mathrm{~mm}$ ) (Elias et al. 2004). Furthermore, behavioral studies confirm that $S$. uetzi females are less likely to mate with a male courting on granite than on filter paper (Hebets 2005). The visual signal manipulations are described above. The experimental arenas consisted of $10.1 \mathrm{~cm}$ diameter acetate cylinders placed either on top of a piece of filter paper in a $10.16 \times 10.16 \times 12.86 \mathrm{~cm}$ Amac Plastic Product box (seismic signal present) (AMAC Plastic Products, PO Box 750249, Petaluma, CA, USA), or the same diameter acetate cylinder attached to the surface of a piece of granite using a glue gun (seismic signal absent). The surface of the rock, as well as the bottom of the plastic box, was painted white to control for both background color (white) and odor across treatments (for diagram of experimental arena, see Figure 1 in Hebets 2005).

All females used in these trials were known virgins of at least $14 \mathrm{~d}$ post-maturation molt and each female was used only once. All males were initially virgins as well. Schizocosa uetzi wolf spiders live only 1 yr, resulting in no overlap of generations. Because individuals were collected from the field as immatures, females did not likely have any prior experience with conspecific mature males. Although $S$. uetzi does overlap with S. stridulans in some areas, exposure to heterospecific $S$. stridulans males does not influence their mate choice of conspecific males (Hebets in press). Males were weighed by placing them into a glass beaker on an analytical balance immediately prior to the start of a trial. Females were placed in their randomly assigned treatment arena and were allowed to acclimate for 2 min before the test male was introduced. Pairs were allowed to interact for 30 min during which time behavioral observations were recorded real-time. Behaviors that were recorded included male courtship, sexual cannibalism, copulation, and when appropriate, the latency to courtship, cannibalism, and/or copulation. One trial consisted of all four treatments and thus, four interacting pairs.

\section{Results}

\section{Quantifying the Visual Signal}

Males varied in weight from 42 to $72 \mathrm{mg}$ with a mean of $53 \mathrm{mg}$ and standard deviation of 6.0. A Shapiro-Wilk W-test (JMP 5.1, SAS, Cary, NC, USA) confirmed that male weights were normally distributed $(\mathrm{W}=0.96, \mathrm{p}=$ 0.18 ). The right tibia of mature males varied in length from 3.09 to $3.78 \mathrm{~mm}$ with a mean of $3.35 \mathrm{~mm}$ and standard deviation of $0.15 \mathrm{~mm}$. Male tibia lengths were also normally distributed ( $\mathrm{W}=0.97, \mathrm{p}=0.2$ ). The percentage of the area of the tibia that was covered in pigmentation ranged from $4 \%$ to $93 \%$ with a mean of $37 \%$ and standard deviation of $0.21 \%$. The actual distribution of individuals with varying degrees of ornamentation can be seen in Figure 1 and fits a lognormal distribution (KSL test, (Kolmogorov, Smirnov, Lilliefors) $\mathrm{D}=0.09, \mathrm{p}=0.15$ ) rather than a normal distribution (Shapiro-Wilk W-test, $\mathrm{W}=0.94, \mathrm{p}=0.01$ ). A Box-Cox Y transformation (JMP 5.1) was performed on the $\%$ tibia pigmented values to generate a normal distribution (after transformation Shapiro-Wilk W-test, $\mathrm{W}=0.98, \mathrm{p}=0.49$ ). The transformed data were used in all future analyses. The contrast values (difference between maximum grayscale value and minimum grayscale value on the tibia) ranged from 42 to 80 with a mean of 59 and a standard deviation of 9.63. The contrast value of males fits a normal distribution (Shapiro-Wilk W-test, $\mathrm{W}=0.98, \mathrm{p}=0.44$ ).

Using the transformed data for \% tibia pigmented, there was a positive correlation with male weight $\left(\mathrm{r}^{2}=0.17, \mathrm{~F}_{(1,52)}=10.46, \mathrm{p}=0.002 ;\right.$ Figure $\left.2 \mathrm{a}\right)$. However,

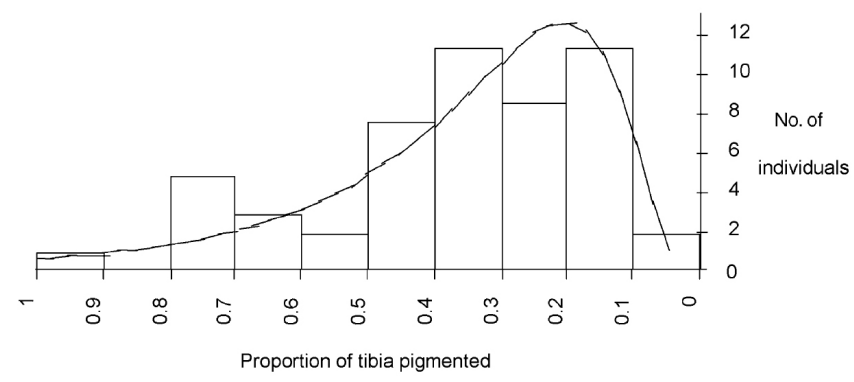

Figure 1. The distribution of males within a population with varying degrees of foreleg pigmentation $(n=54)$. Males range from having more than $90 \%$ of their tibia pigmented to less than $10 \%$ of their tibia pigmented. 
(a)

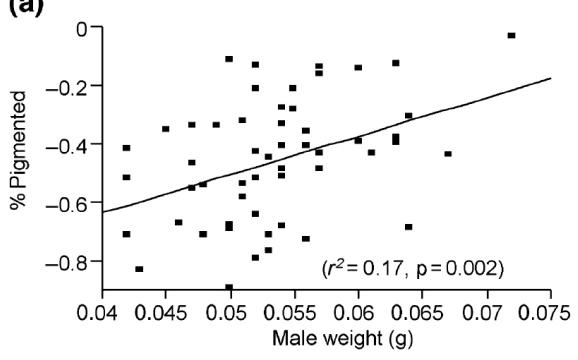

(b)

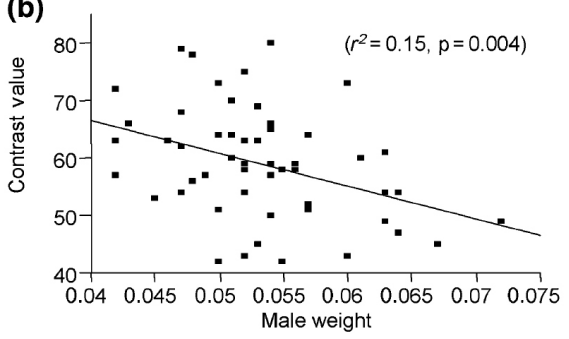

(c)

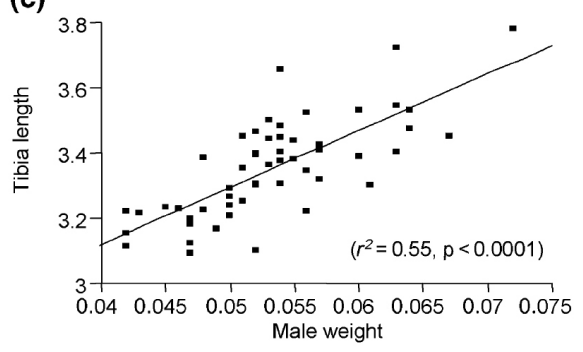

(d)

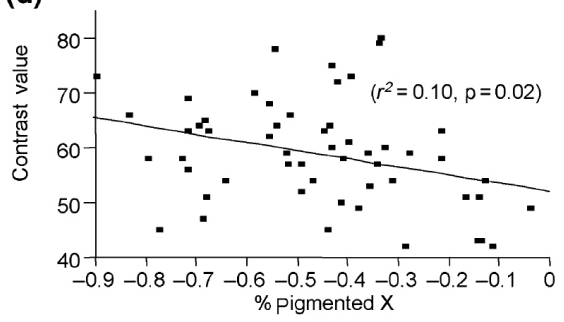

Figure 2. Correlations between male ornamentation and male size $(n=54)$. (a) Positive correlation between male weight and the \% tibia pigmented. (b) Negative correlation between male weight and the contrast value of the pigmentation on the foreleg tibia. (c) Positive correlation between male weight and foreleg tibia length. (d) Negative correlation between the \% tibia pigmented and the contrast value of the pigmentation. there was a negative correlation between the contrast value for male forelegs and male weight $\left(\mathrm{r}^{2}=0.15\right.$, $\mathrm{F}_{(1,52)}=9.01, \mathrm{p}=0.004$; Figure $2 \mathrm{~b}$ ). There was a trend for a positive relationship between the \% tibia pigmented and the tibia length, but this was not significant $\left(\mathrm{r}^{2}=0.07, \mathrm{~F}_{(1,52)}=3.7, \mathrm{p}=0.06\right)$. There was also a trend for a negative relationship between the contrast value and tibia length, but again, this was not significant $\left(\mathrm{r}^{2}=0.05, \mathrm{~F}_{(1,52)}=3.0, \mathrm{p}=0.09\right)$. Male weight and tibia length were strongly correlated with each other $\left(\mathrm{r}^{2}=0.55, \mathrm{~F}_{(1,52)}=64.6, \mathrm{p}<0.0001\right.$; Figure $\left.2 \mathrm{c}\right)$. There was also a negative correlation between the contrast value and the $\%$ of the tibia pigmented $\left(\mathrm{r}^{2}=0.10\right.$, $\mathrm{F}_{(1,52)}=6.0, \mathrm{p}=0.02$; Figure 2d).

\section{Mate-Choice Trials}

One hundred and twelve virgin females and 83 males were used in a total of 112 trials. Twenty-five males were used twice, two males were used thrice, and the remaining 56 males were used only once. There was no difference in average male age across treatments $(\mathrm{bk}+/ \mathrm{s}+$ : mean $\pm \mathrm{SE}=23.62 \pm 1.9 ; \quad \mathrm{bk}+/ \mathrm{s}^{-}: \quad 25.4 \pm 2.2 ; \quad \mathrm{br}+/ \mathrm{s}+$ : $\left.22.9 \pm 2.1 ; \mathrm{br}+/ \mathrm{s}^{-}: 21.1 \pm 2.3 ; \mathrm{F}_{(3,96)}=0.61, \mathrm{p}=0.61\right)$. All females were virgins and were used only once.

A chi-squared analysis using all trials revealed that mating frequency was dependent on experimental treatment $(\mathrm{bk}+/ \mathrm{s}+: \mathrm{n}=31,39 \%$ mated; $\mathrm{bk}+/ \mathrm{s}-: \mathrm{n}=25,12 \%$ mated; $\mathrm{br}+/ \mathrm{s}+: \mathrm{n}=31,39 \%$ mated; $\mathrm{br}+/ \mathrm{s}-: \mathrm{n}=25,4 \%$ mated; $\chi^{2}=16.46, \mathrm{p}=0.009$ ). The seismic environment influenced mating frequency while the visual signal ma- nipulation did not (seismic: $\chi^{2}=10.68, \mathrm{p}=0.001$; visual: $\chi^{2}=0.83, \mathrm{p}=0.36$; seismic $*$ visual: $\chi^{2}=0.83, \mathrm{p}=0.36$ ). An analysis of variance revealed no difference in latency to copulation across treatments $(\mathrm{bk}+/ \mathrm{s}+: \mathrm{n}=12$, mean $\pm \mathrm{SE}=13.2 \pm 2.9 ; \mathrm{bk} / \mathrm{s}^{-}: \mathrm{n}=3,8.4 \pm 5.7 ; \mathrm{n}=12$, br $+/ \mathrm{s}^{+}: \quad 12.7 \pm 2.9 ; \quad \mathrm{br} / \mathrm{s}-: \mathrm{n}=1, \quad 18.8 ; \quad \mathrm{F}_{3,24}=0.32$, $\mathrm{p}=0.81 ;$ seismic: $\mathrm{F}=0.01, \mathrm{p}=0.92 ;$ visual $=0.67$, $\mathrm{p}=0.42$; seismic $*$ visual: $\mathrm{F}=0.8, \mathrm{p}=0.38$ ).

A second analysis was conducted which included only trials in which males were known to have engaged in courtship. Again, a chi-squared analysis revealed that mating frequency was dependent on experimental treatment $(\mathrm{bk}+/ \mathrm{s}+: \mathrm{n}=19,63 \%$ mated; $\mathrm{bk}+/ \mathrm{s}-: \mathrm{n}=20,15 \%$ mated; $\mathrm{br}+/ \mathrm{s}+: \mathrm{n}=22,55 \%$ mated; $\mathrm{br}+/ \mathrm{s}-: \mathrm{n}=19,5 \%$ mated; $\left.\chi^{2}=23.52, \mathrm{p}<0.0001\right)$. As seen in the above analysis, the seismic environment influenced mating frequency while the visual signal manipulation did not (seismic: $\chi^{2}=15.39, \mathrm{p}=0.0001$; visual: $\chi^{2}=1.23$, $\mathrm{p}=0.27$; seismic $*$ visual: $\left.\chi^{2}=0.34, \mathrm{p}=0.56\right)$.

Because many males were used more than once, we restricted our third analysis to include data only for the first trial for every male and only those trials in which males courted $(n=59)$. A chi-squared analysis revealed that mating frequency was dependent on experimental treatment $\left(\chi^{2}=18.21, \mathrm{p}=0.0004\right.$; Figure 3$)$. The seismic environment influenced mating frequency while the visual manipulation did not (seismic: $\chi^{2}=12.86$, $\mathrm{p}=0.0003$; visual: $\chi^{2}=0.48, \mathrm{p}=0.49$; seismic $*$ visual: $\left.\chi^{2}=0.008, \mathrm{p}=0.93\right)$.

Pre-copulatory cannibalism rates did not vary across treatment when analyzing either all the trials together 


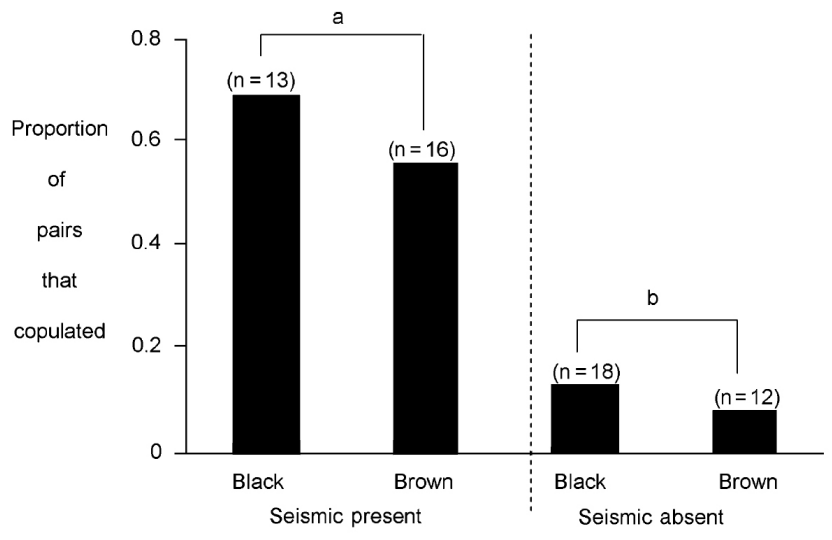

Figure 3. Proportion of pairs that copulated under the different mate choice treatments. Pairs were more likely to copulate in the presence of a seismic signal, but there was no interaction between the visual signal manipulation and the presence/absence of a seismic signal. Different letters indicate significant differences $(p=0.0004)$.

( $\mathrm{n}=112 ; \mathrm{bk}+/ \mathrm{s}+: 6 \%$ cannibalized; bk $+/ \mathrm{s}-: 4 \%$ cannibalized; br $+/ \mathrm{s}+:$ : $10 \%$ cannibalized; br $+/ \mathrm{s}-:$ : $\%$ cannibalized; $\chi^{2}=1.03, \mathrm{p}=0.79$ ) or only the trials in which males engaged in courtship $(\mathrm{n}=80 ; \mathrm{bk}+/ \mathrm{s}+: 5 \%$ cannibalized; bk $+/ \mathrm{s}^{-}: 5 \%$ cannibalized; $\mathrm{br}+/ \mathrm{s}+$ and $\mathrm{br}+/ \mathrm{s}^{-}$: $0 \%$ cannibalized; $\chi^{2}=2.93, \mathrm{p}=0.40$ ). Of the pairs that copulated, post-copulatory cannibalism rates also did not vary across treatments $(\mathrm{n}=28 ; \mathrm{bk}+/ \mathrm{s}+: \mathrm{n}=12,25 \%$ cannibalized; bk $+/ \mathrm{s}-: \mathrm{n}=3,33 \%$ cannibalized; $\mathrm{br}+\mathrm{s}+$ : $\mathrm{n}=12,25 \%$ cannibalized; $\mathrm{br}+/ \mathrm{s}-: \mathrm{n}=1,0 \%$ cannibalized; $\left.\chi^{2}=0.68, \mathrm{p}=0.88\right)$.

\section{Discussion}

While it has been anecdotally known that male $S$. uetzi vary in their degree of foreleg ornamentation, this study represents the first quantification of this variation. As previously suggested (Stratton 1997; Hebets 2003), in a single population, males range from having more than $90 \%$ of their foreleg tibia area covered in pigmentation to less than $10 \%$ covered. We found that the proportion of the tibia covered in pigmentation correlates positively with male weight and thus may be a honest indicator of male mass or past foraging success. Although the proportion of the tibia covered in pigmentation did not correlate significantly with tibia length, the trend was certainly in this direction. In addition, male weight and tibia length were found to be strongly correlated, suggesting that females may be able to ascertain information about both current male condition (via weight) and static male traits (overall body size via tibia length) by assessing the proportion of the tibia covered with pigmentation. However, it is unclear whether females are able to perceive the tibia as a discrete unit, thus enabling them to assess the proportion of pigmented area relative to tibia area vs. simply assessing overall size of the tibia or pigment patch.

The contrast value of the pigmentation was found to have a negative correlation with male weight, with heavier males having a pigmented area that contrasted less with the rest of the tibia than less heavy males. This increased contrast value in less heavy males was achieved through a darker pigmented area rather than a lighter background foreleg color. We also found a negative correlation between the contrast value and the proportion of the tibia pigmented. Our results suggest that the contrast value within the tibia would not provide a female with reliable information about male size or past foraging success; however that is not to say that it does not convey information. For example, the contrast value may be important for conveying other quality information such as male immune function (Ahtiainen et al. 2004). In the damselfly for instance, variation in the darkness of wing pigmentation has been shown to reflect variation in correlated aspects of parasite resistance (Siva-Jothy 2000). Such a function requires further exploration in $S$. uetzi.

Interestingly, there appears to be a trade-off between how much of the tibia is covered in pigmentation vs. the darkness or contrast value of the pigmentation that is present. While it is tempting to think of putative tradeoffs between immune function and size, future studies are necessary to determine whether or not the contrast value conveys information and/or whether or not females use contrast value in mate-choice decisions. Our results also highlight the importance of manipulating not only presence/absence of pigmentation, but also contrast value of pigmentation in order to get a more realistic notion of how and why females are making mate-choice decisions.

While our quantification of the visual signal suggests that females may be able to obtain information about male quality (i.e. weight) via the expression of this foreleg ornamentation, using artificially manipulated males, females in this study did not appear to use foreleg ornamentation as a mate-choice criterion. Pairs mated more frequently in the presence vs. absence of a seismic signal, but there were no differences in mating frequency between males with black forelegs vs. brown forelegs, regardless of the presence/absence of the seismic signal. This seeming lack of a preference for more orna- 
mented males is seen in mate-choice trials of unmanipulated males that vary in foreleg ornamentation as well (E. A. Hebets, pers. obs.). These results suggest that naïve $S$. uetzi females do not have an innate preference for more ornamented males within the range of natural variation, regardless of the seismic signaling environment.

Results of this study beg the question then, why do males have varying degrees of ornamentation, or any ornamentation at all, if females are not using this trait in mate-choice decisions? Foreleg ornamentation in $S$. uetzi is a sexually dimorphic trait that males only acquire upon sexual maturation. The legs that males use in visual leg-waving displays during courtship are the same legs that possess this ornamentation, strongly suggesting a function in courtship, yet females do not appear to distinguish among males based on their foreleg ornamentation.

One potential explanation is that the male foreleg ornamentation is not important in male-female interactions, but instead in male-male interactions. However, male Schizocosa do not appear to have highly stereotyped or ritualized male-male interactions. Furthermore, in mate-choice trials involving two males and one female, the only male-male interactions observed were attempted mounts by one male onto the other male (E. A. Hebets, pers. obs.). Thus, while a function in intrasexual selection cannot be ruled out at this point, such a function seems highly unlikely. A second possibility is that females use the actual interaction between the signals to choose mates. Certain qualities of the seismic signal may be associated with specific qualities of foreleg ornamentation and it may be this combination of information that females use to set their mate-choice threshold or to make mate-choice decisions. Under this hypothetical scenario, by artificially manipulating the males in this experiment, we by definition broke the link between the seismic and visual signal and thus may have thrown off the female's mate-choice criteria. We do not however feel that this scenario is likely because we still observed high mating frequencies in our experiments (approx. 60\% in the presence of a seismic signal). One might predict that if we completely threw off a female's mate-choice criteria by artificially manipulating male foreleg morphologies, our mating frequencies would be extremely low. A third possibility is that the visual and seismic signals may be providing redundant information, allowing for a more accurate female mate-choice decision (Moller \& Pomiankowski 1993; Johnstone 1996; Candolin 2003; Hebets \& Papaj 2005). If the signals do not correspond well to each other, females may ignore the altered signal and in- stead rely only on the unmanipulated signal for mate assessment (Zuk et al. 1993; Hebets \& Papaj 2005). Again this seems very unlikely because previous studies demonstrated that only in the presence of a seismic signal do females distinguish among visual stimuli, suggesting the exact opposite pattern (Hebets 2005).

It is unclear exactly how female $S$. uetzi perceive black vs. brown nail polish in contrast to the rest of the foreleg. Our assumption is that the brown nail polish contrasts less with the foreleg and provides a relatively realistic non-ornamented foreleg. In contrast, we assume that the black nail polish acts in the exact opposite fashion, increasing the contrast and mimicking the contrast value of males with black forelegs. These assumptions may not be valid, however, as it is possible that both colors of nail polish have an equal contrast value in the eyes of the female. The lack of ability of females to distinguish between black and brown painted forelegs could account for our finding that females do not distinguish among males based upon foreleg pigmentation. We again find this to be an unlikely explanation. $S$. uetzi females in an earlier experiment were shown to have the ability to clearly discriminate between males with black vs. brown painted forelegs (Hebets 2003), and unpublished data assessing female mate choice of unmanipulated males support our finding that females do not appear to use male foreleg morphologies in making mate-choice decisions.

Under natural conditions, we propose that the male foreleg ornamentation may play an important role in female mate-choice learning. Subadult female experience has been shown to be important in adult female mate choice in $S$. uetzi. Using the same foreleg manipulations as were used in this study, subadult females exposed to males with black forelegs were found to be more likely to mate with a male with black forelegs as an adult while females exposed to males with brown forelegs were more likely to mate with males with brown forelegs (Hebets 2003). Not only can females distinguish among these manipulated morphologies then, but it is clear that this foreleg pigmentation is also important in learning adult mating preferences. Interestingly, similar to the results of this present study, unexposed females in the above-mentioned experiment did not distinguish among males with black vs. brown forelegs (Hebets 2003). Female $S$. uetzi with no prior experience with mature males appear to have no innate preference for black vs. brown male forelegs.

The possibility remains that the previous inter-signal interaction observed between the visual and seismic 
courtship signals of $S$. uetzi may function during female mate-choice learning and may be relevant only for experienced females. In the absence of knowledge about the distribution or prevalence of males of varying morphologies, females may be less likely to demonstrate choosiness. Because the females used in this study were inexperienced with mature males, they may have simply accepted any conspecific male, regardless of the male's degree of ornamentation. In an experiment examining the influence of experience with heterospecific males on subsequent adult female mate choice, it was suggested that the seismic signal for $S$. uetzi is a password for visual signal learning (Hebets in press). In other words, in the presence of a conspecific seismic signal, a subadult female may focus its visual attention on the present courting male and this experience may help shape the female's subsequent adult mate choice of male foreleg pigmentation. While this seems like a plausible function, again future studies are needed to confirm an intersignal interaction during female mate-choice learning.

In conclusion, this study suggests that while $S$. uetzi females may be able to obtain information about male quality from one component of the male's visual courtship signal (foreleg pigmentation), their use of this information is not forthright. Future studies incorporating individual female experience will likely shed more light onto the function of multimodal signaling in this species.

\section{Acknowledgements}

The spiders used in this study were collected with the help of G. Stratton and P. Miller. Becky Heinig aided in painting spider forelegs and D. Nee helped with matechoice trials. The research was supported in part by an NIH training grant for the Department of Neurobiology and Behavior at Cornell University and by NIH funding to R. Hoy. The research was conducted in the laboratory of R. Hoy. Valuable insights and discussion were provided by R. Hoy, D. Elias, N. VanderSal, K. Fowler-Finn, A. Spence, J. Storz, A. Basolo, W. Wagner, and the Basolo and Wagner lab group at University of Nebraska-Lincoln.

\section{Literature Cited}

Ahtiainen, J. J., Alatalo, R. V., Kortet, R. \& Rantala, M. J. 2004: Sexual advertisement and immune function in an arachnid species (Lycosidae). Behav. Ecol. 15, 602-606.
Candolin, U. 2003: The use of multiple cues in mate choice. Biol. Rev. 78, 575-595.

Elias, D. O., Mason, A. C. \& Hoy, R. R. 2004: The effect of substrate on the efficacy of seismic courtship signal transmission in the jumping spider Habronattus dossenus (Araneae: Salticidae). J. Exp. Biol. 207, 4105-4110.

Hebets, E. A. 2003: Subadult experience influences adult mate choice in an arthropod: exposed female wolf spiders prefer males of a familiar phenotype. Proc. Natl Acad. Sci. USA 100, 13390-13395.

Hebets, E. A. 2005: Attention-altering interaction in the multimodal courtship display of the wolf spider Schizocosa uetzi. Behav. Ecol. 16, 75-82.

Hebets, E. A. (in press): Subadult female experience does not influence species recognition in the wolf spider Shizocosa uetzi Stratton 1997. J. Arachnol., in review.

Hebets, E. A. \& Papaj, D. R. 2005: Complex signal function: developing a framework of testable hypotheses. Behav. Ecol. Sociobiol. 57, 197-214.

Hebets, E. A. \& Uetz, G. W. 1999: Female responses to isolated signals from multimodal male courtship displays in the wolf spider genus Schizocosa (Araneae: Lycosidae). Anim. Behav. 57, 865-872.

Hebets, E. A. \& Uetz, G. W. 2000: Leg ornamentation and the efficacy of courtship display in four species of wolf spider (Araneae: Lycosidae). Behav. Ecol. Sociobiol. 47, 280-286.

Hebets, E. A., Stratton, G. E. \& Miller, G. L. 1996: Habitat and courtship behavior of the wolf spider Schizocosa retrorsa (Banks) (Araneae, Lycosidae). J. Arachnol. 24, 141-147.

Johnstone, R. A. 1996: Multiple displays in animal communication: 'backup signals' and 'multiple messages'. Phil. Trans. R. Soc. Lond. B - Biol. Sci. 351, 329-338.

McClintock, W. J. \& Uetz, G. W. 1996: Female choice and pre-existing bias: visual cues during courtship in two Schizocosa wolf spiders (Araneae: Lycosidae). Anim. Behav. 52, 167-181.

Møller, A. P. \& Pomiankowski, A. 1993: Why have birds got multiple sexual ornaments. Behav. Ecol. Sociobiol. 32, 167-176.

Scheffer, S. J., Uetz, G. W. \& Stratton, G. E. 1996: Sexual selection, male morphology, and the efficacy of courtship signalling in two wolf spiders (Araneae: Lycosidae). Behav. Ecol. Sociobiol. 38, 17-23.

Siva-Jothy, M. 2000: A mechanistic link between parasite resistance and expression of a sexually selected trait in a damselfly. Proc. R. Soc. Lond. B - Biol. Sci. 267, 2523-2527.

Stratton, G. E. 1983: Comparison of courtship behaviors and interspecific crosses in the Schizocosa-Ocreata species complex (Araneae, Lycosidae). Am. Zool. 23, 967-967. 
Stratton, G. E. 1997: A new species of Schizocosa from the southeastern USA (Araneae, Lycosidae). J. Arachnol. 25, 84-92.

Stratton, G. E. \& Lowrie, D. C. 1984: Courtship behavior and life-cycle of the wolf spider Schizocosa-Mccooki (Araneae, Lycosidae). J. Arachnol. 12, 223-228.

Stratton, G. E. \& Uetz, G. W. 1981: Acoustic communication and reproductive isolation in 2 species of wolf spiders. Science 214, 575-577.

Stratton, G. E. \& Uetz, G. W. 1986: The inheritance of courtship behavior and its role as a reproductive isolating mech- anism in 2 species of Schizocosa wolf spiders (Araneae, Lycosidae). Evolution 40, 129-141.

Uetz, G. W. \& Denterlein, G. 1979: Courtship behavior, habitat, and reproductive isolation in Schizocosa-Rovneri Uetz and Dondale (Araneae, Lycosidae). J. Arachnol. 7, 121-128.

Zuk, M., Ligon, J. D. \& Thornhill, R. 1993: Effects of experimental manipulation of male secondary sex characteristics on female mate preference in red jungle fowl. Anim. Behav. 44, 999-1006. 